\title{
Modeling and Temperature Control System Design of Heating Furnace for Thermoforming Machine
}

\author{
Shaoke Chen \\ Mechatronic and Electronic Engineering Department, Shantou University, Shantou, Guangdong 515063, China \\ ${ }^{*}$ Corresponding author
}

\begin{abstract}
The temperature control of the heating furnace has a great influence on the quality of the product. Too high temperature or too low will make the product disqualified. Based on a company's thermoforming machine, this paper analyzes the function of the heating system of the thermoforming machine in the whole equipment, as well as its structure, design principle, heating mode and so on. For the characteristics of the temperature field of the heating system of the thermoforming machine, the heat rise curve of the sheet is obtained by the heating simulation experiment of the sheet. The temperature control system suitable for sheet metal heating is developed. The experimental results show that the scheme can meet the specific requirements of the process, the temperature control is accurate, the reaction is sensitive, and the expected purpose is achieved.
\end{abstract}

Keywords-thermoforming machine; temperature control; heating furnace; self-tuning; PID

\section{INTRODUCTION}

A thermoforming machine is a machine that is heated to a certain temperature of PE, PP and PC. The plastic sheets through a heating device, and then formed by a mold. The heating system is the main part of the thermoforming machine. The sheet material is sent to the furnace by the feeding mechanism to the heater and the heated sheet is sent to the mold, then shutting the mold, blowing or suction to make the sheet formed in the mold. After forming mold again pressed to achieve punched position and punching, opening the mold, blowing the products and sheet separation or collecting mechanism for product collection $[1,2]$.

The heating furnace of the thermoforming machine is the main energy consuming part of the thermoforming machine. At present, there are many problems in domestic enterprises, such as relatively backward technology, low level of automation and intelligentization, and high energy consumption. Most of them is to use the change of the series connection resistance to control the temperature of the furnace. The temperature control mode is the temperature control meter and the voltage regulation module Without PLC control, energy consumption is serious and cannot be effectively controlled. This design uses heating matrix module and precise sensing technology. In PLC application, the analog signal of temperature detection technology is converted to digital voltage signal. By using the PID algorithm, a temperature intelligent controller with high performance price ratio is designed. It has the advantages of accurate temperature control and sensitive reaction $[3,4]$.

\section{ANALYSIS AND CALCULATION OF THERMAL RADIATION FOR EXPERIMENTAL MODEL}

The heating matrix module composed of $10 * 5$ pieces of heating sheet. The heating furnace consists of two heating matrix modules. The plastic sheet is driven by the conveyor belt and is heated between the two matrix module. The heated diathermy medium of thermoforming is the air that does not participate in thermal radiation. Thermal radiation is the process of transmitting energy to the outside in the form of electromagnetic waves. For the convenience of calculation, it is assumed that the surface of the analysis is a fictitious closed space. Each piece of heating is regarded as a small plane, the radiation heat transfer is analyzed and calculated between the small plane and the middle sheet. And then consider the radiation around it [5].

\section{A. Calculation of Radiant Heat Transfer of Heated Sheet}

From the formula of radiation heat transfer calculation, a radiative formula for a piece of heating sheet is obtained:

$$
\begin{aligned}
& \Phi_{i, 0}^{\prime}=\frac{E_{b i}-E_{b 0}}{\frac{1-\varepsilon_{i}}{\varepsilon_{i} A_{i}}+\frac{1}{A_{i} F_{i, 0}}+\frac{1-\varepsilon_{0}}{\varepsilon_{0} A_{0}}} \\
& =\frac{A_{i}\left(E_{b i}-E_{b 0}\right)}{\left(\frac{1}{\varepsilon_{i}}-1\right)+\frac{1}{F_{i, 0}}+\frac{A_{i}}{A_{0}}\left(\frac{1}{\varepsilon_{0}}-1\right)}
\end{aligned}
$$

Where: $i$ is the block $i$ heating piece, and 0 is sheet.

$\varepsilon i$ is the radiant rate of the heated tile, the range of value is 0.85- 0.95 , take 0.9 here.

$\varepsilon 0$ is the radiant rate of the sheet, the value is 0.91 .

The four-square law can be obtained: 


$$
\Phi_{i, 0}^{\prime}=\frac{A_{i} \times 5.67\left[\left(\frac{T_{i}}{100}\right)^{4}-\left(\frac{T}{100}\right)^{4}\right]}{\left(\frac{1}{\varepsilon_{i}}-1\right)+\frac{1}{F_{i, 0}}+\frac{A_{i}}{A_{0}}\left(\frac{1}{\varepsilon_{0}}-1\right)}
$$

In the formula, according to the model, Fi,0 take 0.55 , Ti is the thermodynamic temperature of the heating plate; $\mathrm{T}$ is the thermodynamic temperature of the sheet. As the temperature of the sheet is heated from the initial temperature of $\mathrm{T} 0$ to the set value of Ts, its radiation energy varies with temperature, the (2) integral can be obtained:

$$
\Phi_{i, 0}=\int_{T_{0}}^{T_{s}} \Phi_{i, 0}^{\prime} d T=\frac{A_{i} \times 5.67}{\left(\frac{1}{\varepsilon_{i}}-1\right)+\frac{1}{F_{i, 0}}+\frac{A_{i}}{A_{0}}\left(\frac{1}{\varepsilon_{0}}-1\right)}\left[\left(\frac{T_{i}}{100}\right)^{4}\left(T_{s}-T_{0}\right)-\frac{1}{5 \times 10^{8}}\left(T_{s}^{5}-T_{0}^{5}\right)\right]
$$

Put data into and can be calculated as follows:

$$
\Phi \mathrm{i}, 0=6.97 \times 10-8 \mathrm{Ti} 4-1732
$$

\section{B. Calculation of Heat Dissipation Around Four Sides}

Take the heated tile and radiate heat from the air around it. The air is a blackbody with a radiation rate of 1 . The heating dissipation model is shown in Figure I.

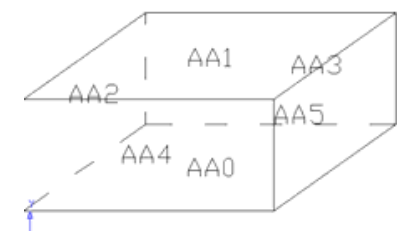

\section{FIGURE I. FOUR SIDES HEATING DISSIPATION MODEL}

The angle coefficient can be obtained according to the model check chart:

$$
\begin{aligned}
\text { FAA } 1-\mathrm{AA} 2 & =\text { FAA } 1-\mathrm{AA} 5=0.20 ; \text { FAA } 1-\mathrm{AA} 3 \\
& =\text { FAA } 1-\mathrm{AA} 4=0.03
\end{aligned}
$$

The calculation formula for side heat dissipation:

$\Phi_{2}=\frac{A A_{1}\left(E_{b 1}-E_{b 2}\right)}{\left(\frac{1}{\varepsilon_{1}}-1\right)+\frac{1}{F_{A 11-A A 2}}}+\frac{A A_{1}\left(E_{b 1}-E_{b 5}\right)}{\left(\frac{1}{\varepsilon_{1}}-1\right)+\frac{1}{F_{A A 1-A A 5}}}+\frac{A A_{1}\left(E_{b 1}-E_{b 3}\right)}{\left(\frac{1}{\varepsilon_{1}}-1\right)+\frac{1}{F_{A A 1-A A 3}}}+\frac{A A_{1}\left(E_{b 1}-E_{b 4}\right)}{\left(\frac{1}{\varepsilon_{1}}-1\right)+\frac{1}{F_{A 11-A A 4}}}$

$$
\text { Where: } E_{b 2=} E_{b 3=} E_{b 4=} E_{b 5=} 5.67 \times\left(\frac{T_{h}}{100}\right)^{4} \text {, Th is the }
$$
ambient temperature of the heating furnace, is $30^{\circ} \mathrm{C}$, which is $303 \mathrm{~K}$.
When sheet is heated from $30^{\circ} \mathrm{C}$ to $200{ }^{\circ} \mathrm{C}$ in the heating tile, the ambient air (black body) is also heated at the same time. So, the total heat dissipation is:

$$
\begin{aligned}
& \int_{T 0}^{T S} \Phi 2 \mathrm{dTk}=5.1 \times 10-8 \mathrm{Ti} 4-1267.314+0.85 \times 10-8 \mathrm{Ti} 4- \\
& 211.219=5.95 \times 10-8 \mathrm{Ti} 4-1478.53 \text {. }
\end{aligned}
$$

\section{Calculation of Sheet Absorption Heat}

Analysis of energy conversion from sheet angle. The absorbed energy of the sheet can be calculated in the following form:

$$
J=C_{P} m \Delta t=C_{P} \rho A_{0} d\left(T_{s}-T_{0}\right)
$$

Where: Cp-- Specific heat of the sheet. $1.9 \mathrm{KJ} / \mathrm{kg} \cdot{ }^{\circ} \mathrm{C}$;

$$
\rho \text {-- Sheet density. } 910 \mathrm{Kg} / \mathrm{m}^{3} \text {; }
$$

A0, d-- Heated part sheet area, $0.02 \mathrm{~m} 2$ and thickness, $0.0012 \mathrm{~m}$.

Ts, T0-- Setting temperature of the sheet $473 \mathrm{~K}$ and the initial temperature $303 \mathrm{~K}$ respectively.

The put data and calculation can be obtained:

$\mathrm{J}=1900 \times 910 \times 0.0012 \times 0.02 \times 170 \mathrm{~J}=7054.32 \mathrm{~J}$

\section{Temperature Setting of Heating Sheet}

According to the conservation of the system energy, it can be obtained:

$$
\mathrm{J} / \mathrm{t}=\Phi \mathrm{i}-0-\Phi 2
$$

In the formula, $t$ is the heating time of the sheet, $t=10 \mathrm{~s}$. Replace the value and obtain:

$$
(5.95 \times 10-8 \mathrm{Ti} 4-1478.53)+705.43=6.97 \times 10-8 \mathrm{Ti} 4-1732
$$

Final: $\mathrm{Ti}=280.7^{\circ} \mathrm{C}$

\section{DESIGN OF SySTEM CONTROL SCHEME}

In the double loop of the control system, the temperature feedback of the sheet is introduced to the control system as the basis for determining the temperature of the heater. The set temperature of the heater is closed loop control temperature of the heater. To adjust the temperature of the heater itself, a cascade control system is formed.

The cascade control system is composed of a main circuit and a secondary circuit, as shown in Figure 2. The output of the main circuit is as a given value of the secondary circuit. To achieve the stability of the amplitude of the controlled quantity, the output of the secondary circuit is used as the control quantity 
to control the controlled object. It is guaranteed that the sheet temperature will not affect the quality of the sheet during the dynamic process. At the same time, the speed of increasing the temperature is guaranteed.

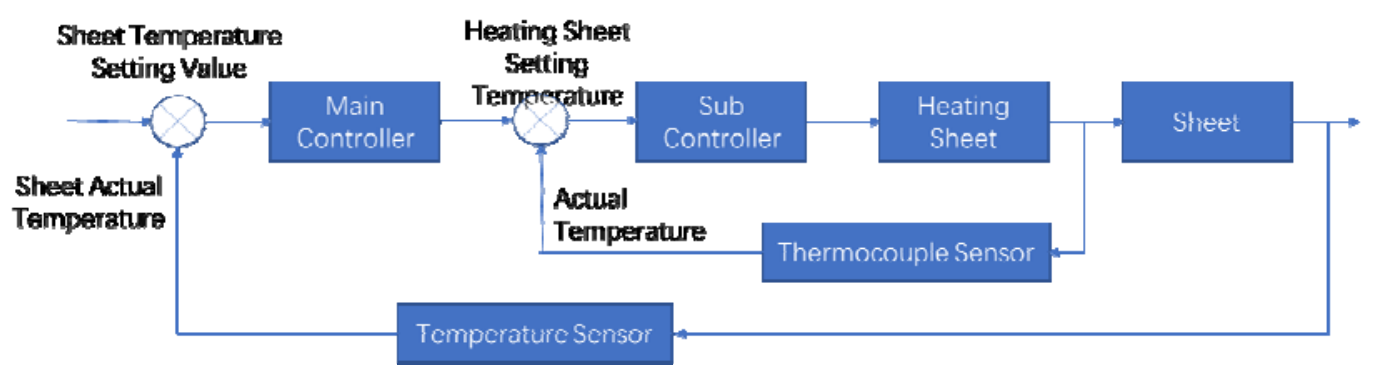

FIGURE II. PRINCIPLE BLOCK DIAGRAM OF SYSTEM DESIGN

The temperature is as the control object in the system. In the heating system of the thermoforming machine, there are five rows of heating tiles each of the upper and lower heating furnaces, and a total of 50 pieces are distributed. One areas that every 5 pieces of heating tiles control the temperature of a region. That is, there are 10 areas in total. Using S7-300PLC realize the monitoring and control of the temperature.

\section{Temperature CONTROL Design}

\section{A. Hardware Design of Control System}

The main hardware parts in this design include the selection of PLC, the input module, the output module, the temperature probe, the type of thermocouple, and the selection of other hardware devices.

\section{B. Software Design of Control System}

This program needs to control the temperature of the 10 loop and measure the parameters of each circuit. For the same

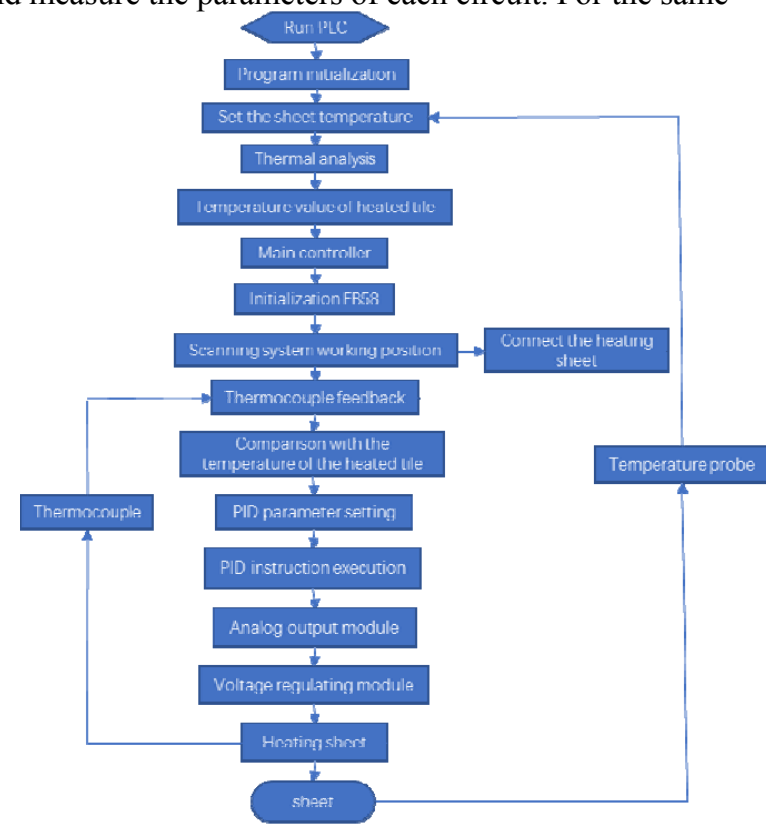

FIGURE III. GENERAL PROGRAM FLOW CHART functionality, encapsulating a process block in a process. The program structure can be simplify by calling the main program. The PID operation block is placed in a Loop interrupt block. In order to reduce the burden of CPU, the method of setting the timer count judgment makes the PID operation of 2 circuits running into the loop interrupt block each time. The overall program flow chart is shown in Figure 3.

The system realizes the measurement of the maximum temperature, overshoot, maximum deviation, rise time, peak time and adjustment time of the system, and is expressed by the temperature curve.

\section{SIMULATION EXPERIMENT}

Setting up a monitoring picture in a graphic editing area. The main monitoring interface is shown in Figure 4.

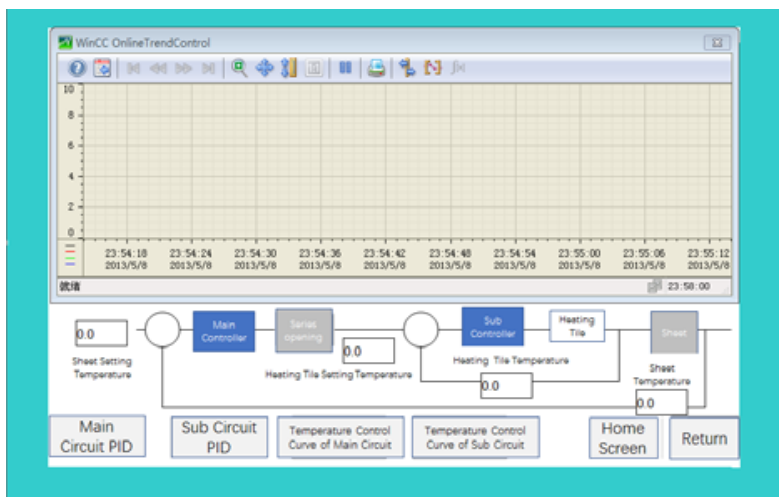

FIGURE IV. MAIN CONTROL INTERFACE 
First, the system is self-tuning the parameters. Before tuning, a set of experience parameters is selected as $\mathrm{K}=2, \mathrm{Ti}=400$, $\mathrm{Td}=100$. The set value of the sheet temperature is 90 . The step by step approximation method is adopted (the PI control method is adopted in the sub loop, and the PID control method is adopted in the main loop). First close the main loop and set sub loop. The tuning of sub loop as a whole object is added to the main loop for the tuning of the main loop. The tuning curve is

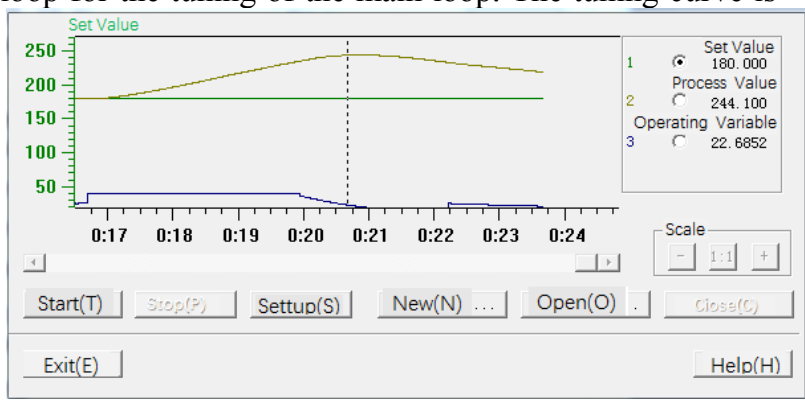

FIGURE V. SUB LOOP TUNING CURVE shown as shown in Figure 5,6. After that, the main loop and the sub loop are kept in the open state. Cycle tuning of sub loop and main loop. The stability of the sub loop is higher at the second tuning. Otherwise the whole time will go awry. Table 1 is a multi - tuning PID parameter record. After tuning the parameters of the main and sub controller obtain the curve of the system as shown in Figure 7 (the set value of the sheet is $80^{\circ} \mathrm{C}$ ).

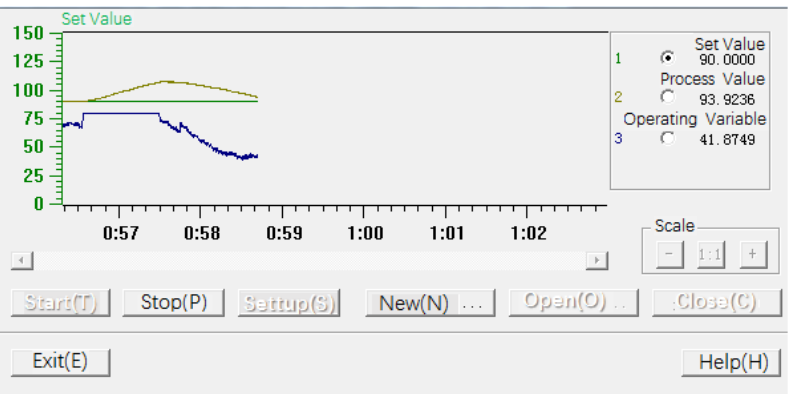

FIGURE VI. MAIN LOOP TUNING CURVE

TABLE I. PID PARAMETER RECORDS OF MULTIPLE TUNING

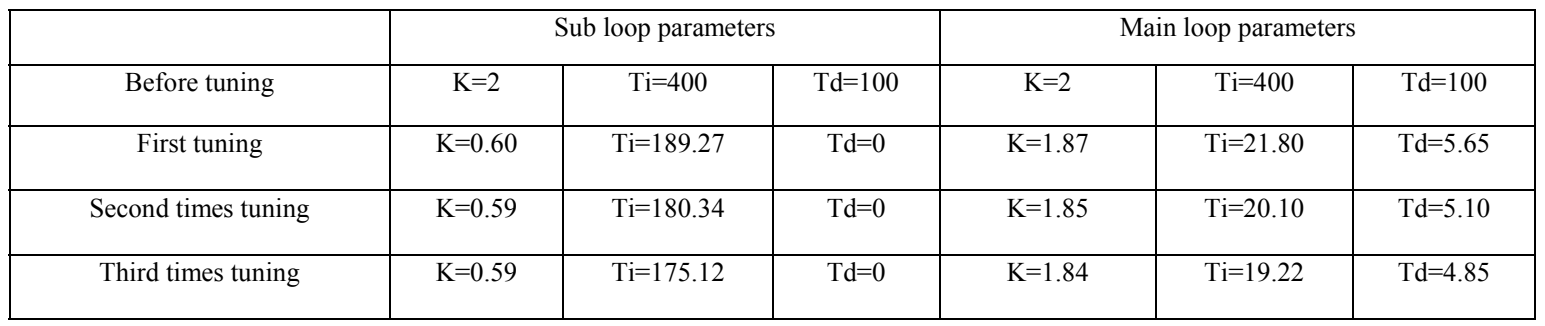

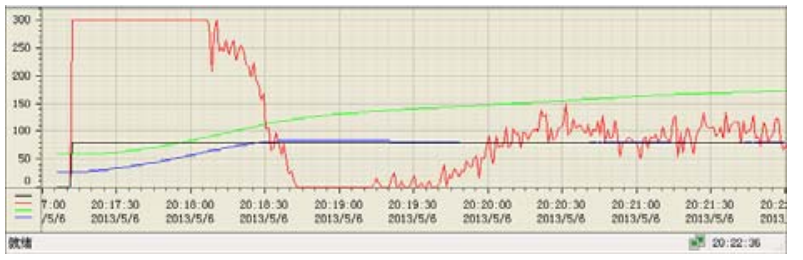

FIGURE VII. TEMPERATURE CONTROL SYSTEM CURVE

(Red line - heating tile temperature setting value; Green line heating tile practical value; Purple line -Actual value of sheet temperature; Black line - sheet temperature setting value)

As shown in Figure VII, the temperature curve of the sheet has a small rising time, the overshoot is small, the stability is fast, and the design requirements are basically reached.

\section{SUMMARY}

After the temperature control system is completed, the experiment was carried out through the experimental platform. In the test, the self-tuning parameters are applied, the overshoot is small and the steady-state error is within 0.5 degrees. At the same time, the temperature curve of the experimental PID circuit is good. The design basically meets the temperature intelligent control requirements of the thermoforming machine. The temperature field of a heating furnace has a direct relationship with the above aspects. It needs to be carefully modeled and analyzed. According to the analysis results, the appropriate control scheme is formulated to realize the intelligent and energy-saving control of production. It is of great significance to improve the technical level of the domestic thermoforming machine and enhance the market competitiveness of the domestic thermoforming machine.

\section{REFERENCES}

[1] Chy Md. Muminul Islam, Boulet Benoit, Haidar Ahmad, A model predictive controller of plastic sheet temperature for a thermoforming process, Proceedings of the American Control Conference. 2011 4410-4415.

[2] ZHANG Junbo1, LUO Qingqing, ZHENG Jianxiong, Discussion on Development Trend of Thermoforming Machine, J. Mechanical \& Electrical Engineering Technology.2013 42(6) 213-214.

[3] CHEN Shaoke, SHU Jun, CHEN Qiongyan, Application and Design of Automatic Control System for the Thermoforming Machine, J. Packaging Engineering.2015 36(1) 116-120.

[4] Belforte Guido, Colombo Federico, Raparelli Terenziano etc., Study of the press forming mechanism of a thermoforming machine, Journal of Mechanical Engineering Science. 2014 228(10) 1715-1723.

[5] Chy Md Muminul Islam, Boulet Benoit, Iterative learning model predictive controller of plastic sheet temperature for a thermoforming process, Proceedings of the American Control Conference. 2012 627-633. 